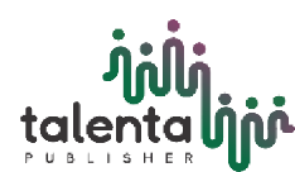

Jurnal Dinamis

Vol. 9, No. 1, Bulan Tahun | 06-21

ISSN : 0216-7492, e-ISSN : 2809-3410

Homepage : https://talenta.usu.ac.id/dinamis

\title{
IDENTIFIKASI EKSPERIMENTAL VIBRASI PADA SISTEM TRANSMISI MESIN SLUDGE SEPARATOR
}

\author{
Prakarsa Ade Putra Surbakti ${ }^{1 *}$, Muhammad Sabri ${ }^{2}$ \\ Departemen Teknik Mesin, Fakultas Teknik, Universitas Sumatera Utara, Kota Medan, 20222, Indonesia \\ *Email: prakarsasurbakti@gmail.com
}

\begin{abstract}
ABSTRAK
Dalam pabrik kelapa sawit (PKS) terdapat mesin sludge separator yang berfungsi sebagai pemisah lumpur (sludge) dan minyak kelapa sawit (palm oil). Kondisi kelayakan mesin sangat berpengaruh terhadap hasil pengolahan. Namun dengan besarnya putaran yang terjadi pada sistem transmisi, bowl disk dan komponen yang lain, sehingga membuat munculnya getaran yang terjadi pada mesin yang dapat mempengaruhi kondisi dan kinerja dari mesin tersebut. Oleh karena itu untuk perawatan secara prediktif penulis akan melakukan analisa getaran (vibrasi) yang terjadi pada sistem transmisi (worm gear) sludge separator dan menentukan kondisi mesin sludge separator berdasarkan analisa data vibrasi yang diukur dengan melakukan pengujian langsung ke pabrik kelapa sawit kebun adolina. Pengukuran dilakukan di 6 titik kritis dengan menggunakan vibration meter, dengan melakukan 3 aksis yaitu aksial, horizontal dan vertikal. Data getaran berupa kecepatan getaran dan di plot ke grafik menggunakan aplikasi exel untuk mendapatkan grafik time domain. Hasil pengukuran menunjukkan bahwa amplitudo aksial terbesar terjadi pada pada titik 6 dengan kecepatan getaran $3,22 \mathrm{~mm} / \mathrm{s}$, amplitudo horizontal terbesar terjadi pada titik 5 dengan $5,54 \mathrm{~mm} / \mathrm{s}$ dan amplitudo vertikal terbesar terjadi pada titik 5 dengan $5,72 \mathrm{~mm} / \mathrm{s}$. Displacement terbesar terjadi pada arah vertikal pada titik 6 sebesar 0,376 mm. Karakteristik kerusakan pada titik 1,2 belum terlihat karena pengukuran dilakukan pada putaran rendah. Sedangkan karakteristik kerusakan pada titik 3,4,5,6 adalah gejala Kelonggaran Mekanik. Tingkat keadaan yang sudah melampaui batas normal terdeteksi karena munculnya sinyal amplitudo tinggi pada arah horizontal dan vertikal sedangkan tidak muncul di arah aksial (ISO 10816, ISO 2372).
\end{abstract}

Kata kunci: Perawatan, Analisis Getaran, Vibrasi

\begin{abstract}
In a palm oil mill there is a sludge separator machine that functions as a separator for sludge and palm oil. The condition of the feasibility of the machine greatly affects the processing results. However, with the large rotation that occurs in the transmission system, disk bowl and other components, it causes vibrations that occur in the engine which can affect the condition and performance of the machine. Therefore, for predictive maintenance, the author will analyze the vibrations that occur in the transmission system (worm gear) of the sludge separator and determine the condition of the sludge separator machine based on the analysis of vibration data measured by conducting direct testing at the Adolina plantation palm oil mill. Measurements are carried out at 6 critical points using a vibration meter, by doing 3 axes, namely axial, horizontal and vertical. The vibration data is in the form of vibration velocity and is plotted to a graph using the exel application to obtain a time domain graph. The measurement results show that the maximum axial amplitude occurs at point 6 with a velocity of 3,22 $\mathrm{mm} / \mathrm{s}$, the largest horizontal amplitude occurs at point 5 with 5,54 $\mathrm{mm} / \mathrm{s}$ and the largest vertical amplitude occurs at point 5 with $5,72 \mathrm{~mm} / \mathrm{s}$. The largest displacement occurs in the vertical direction at point 6 of 0,376 mm. The damage characteristic at point 1,2 has not been seen because the measurement was carried out at low rotation. While the characteristics of the damage at point 3,4,5,6 are the symptoms of Mechanical Looseness. A state level that has exceeded the normal limit is detected because of the appearance of a high amplitude signal in the horizontal and vertical directions while it does not appear in the axial direction (ISO 10816, ISO 2372).
\end{abstract}

Keywords: Maintenance, Vibration Analysis, Vibration 


\section{PENDAHULUAN}

Kelapa sawit mengalami proses panjang sebelum diolah menjadi minyak yang siap digunakan untuk berbagai kebutuhan. Dalam Pabrik kelapa sawit (PKS) Memasuki stasiun pemurnian, minyak masih banyak mengandung kotoran- kotoran yang berasal dari daging buah seperti lumpur, air dan lain- lain. Pada stasiun ini salah satu dari beberapa unit alat pengolah untuk memurnikan minyak produksi adalah Sludge Separator. Penelitian sebelumnya pada mesin sludge separator telah dilakukan analisa kegagalan yang terjadi pada mesin tersebut dengan beberapa hasil yang ditemukan seperti roda gigi cacing yang aus, bowl disc yang rusak, nozzle tersumbat hingga seal ring bocor dengan penyebab terjadinya yang bermacam- macam.

Pada penelitian ini penulis berfokus pada Sludge Separator Centrifuge. Dengan besarnya putaran yang terjadi pada sistem transmisi, bowl disk dan komponen yang lain sehingga membuat munculnya getaran yang terjadi pada mesin tersebut. Analisa vibrasi sangat penting karena salah satu indikator terbaik untuk mendeteksi masalah mekanis untuk peralatan berputar, karena getaran suatu mesin yang disebabkan oleh gaya berulang seperti ketakseimbangan, misalignment, poros bengkok, kerusakan bantalan, kelonggaran mekanik, gear aus, kavitasi dan resonansi (Suhardjono 2004) .Oleh karena itu penulis mengidentifikasi getaran yang terjadi pada mesin sludge separator tersebut apakah sesuai dengan batas yang diperbolehkan atau melebihi batas dari standar.

\section{TEORI DASAR}

\subsection{Sludge Separator}

Sludge separator bekerja untuk memisahkan elemen padat dan cair. Model dari alat ini adalah sentrifugal dengan mangkuk berbentuk padat dan selalu berotasi selama proses pemisahan. Kinerjanya dengan memanfaatkan sistem putaran mangkuk yang telah dipasang dan dilepaskan keluar melalui discharge nozzle. Tingkat keberhasilan memisahkan minyak dari elemen padat akan tergantung dari kualitas alat yang digunakan. Dengan menggunakan wastewater sludge centrifuge, proses dalam pabrik kelapa sawit akan berjalan lebih lancar. Dimana sludge yang memiliki berat jenis (bj) > 1,0 (heavy phase) akan terlempar keluar sedangkan minyak yang memiliki berat jenis lebih ringan (light phase) akan terkumpul di tengah bowl melalui discharge pipe untuk dikirim kembali ke continuous settling tank. (Mesin PKS. 2020).

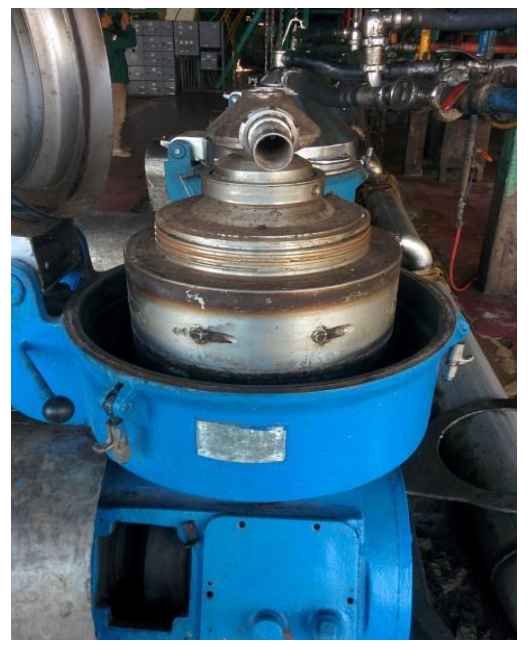

Gambar 2.1 Sludge Separator

\subsection{Analisa Getaran}

Perawatan mesin tradisional, skedul overhaul perbaikan biasanya sulit dibuat karena kebutuhan perbaikan tidak dapat ditentukan secara pasti, tanpa membongkar mesin yang bersangkutan. Bila untuk mendeteksinya kasus permasalahan harus sudah cukup serius, kemungkinan besar kerusakan sudah terjadi dan merambat ke peralatan lain, ataupun peralatan mesin yang bekerja baik yang diperbaiki, sebaliknya peralatan yang akan mengalami kerusakan tidak disentuh, sehingga biaya perbaikan meningkat.

Teknologi modern memungkinkan cara untuk mendeteksi awal gejala kerusakan mekanik maupun elektrikal pada peralatan mesin dari luar, yang paling efektif dari berbagai cara yang mungkin adalah analisa getaran, sehingga analisa getaran menjadi pilihan teknologi predictive maintenance yang paling sering digunakan saat ini ${ }^{[8]}$. 
Tiga sifat fundamental yang berhubungan pada reaksi getaran yang timbul diakibatan oleh adanya transfer gaya siklik melalui elemen-elemen mesin yang ada, dimana elemen-elemen tersebut saling beraksi satu sama lain dan energi disipasi melalui struktur dalam bentuk getaran seperti pada sistem pegas-massa ${ }^{[8]}$, fundamental tersebut yaitu:

1. Massa (m):

Merupakan inersia untuk mempertahankan keadaan semula atau bergerak dari gaya-gaya yang bekerja, satuannya dalam $\mathrm{kg}$; lb

2. Kekakuan/stiffness (k):

Kemampuan untuk mempertahankan dari gaya yang dipersyaratkan bekerja untuk membengkokan (defleksi) struktur yang dengan jarak tertentu, satuannya dalam $\mathrm{N} / \mathrm{m}$; lb/in.

3. Damping/redaman (c):

Mekanisme inheren untuk memperlambat gerakan (kecepatan), satuannya dalam N/(m/s); lb.sec/in

Efek ketiga fundamental tersebut massa, kekakuan, redaman menentukan bagaimana suatu sistem akan merespon energi getaran yang bekerja. Kerusakan atau keausan akibat umur pemakaian peralatan dan deformasi akan mengubah karakteristik dinamik sistem dan cenderung meningkatkan energi getaran. Adanya perubahan ini dideteksi untuk dianalisa.

\subsubsection{Karakteristik Getaran}

Getaran secara teknik didefenisikan sebagai gerak osilasi dari suatu objek terhadap posisi objek awal/diam. Kondisi getaran suatu mesin dan masalah-masalah mekanik yang terjadi dapat diketahui dengan mengukur karakteristik getaran yang timbul. Karakteristik utama getaran yaitu:

1. Frekuensi merupakan karakteristik dasar pengukuran dan menggambarkan jumlah gerak osilasi tiap detik.

2. Perpindahan mengindikasikan berapa jauh suatu objek bergetar

3. Kecepatan mengindikasikan berapa cepat objek bergetar

4. Percepatan mengindikasikan suatu objek bergetar terkait dengan gaya penyebab getaran

5. Phase mengindikasikan bagaimana suatu bagian bergetar relatif terhadap bagian yang lain, atau untuk menentukan posisi suatu bagian yang bergetar pada suatu saat, terhadap suatu referensi atau terhadap bagian lain yang bergetar dengan frekuensi yang sama.

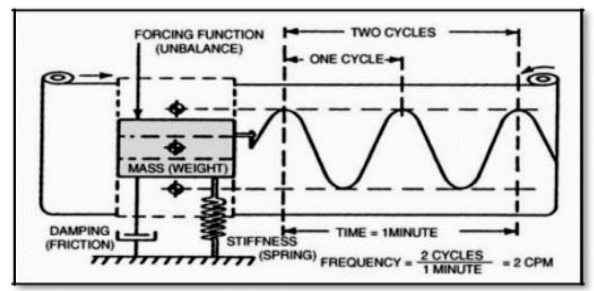

Gambar 2.2 Sistem Getaran Sederhana ${ }^{[6]}$



Gambar 2.3 Hubungan Antara Perpindahan, Kecepatan dan Percepatan Getaran ${ }^{[6]}$

Panjang gelombang adalah sebuah jarak antara satuan berulang dari sebuah pola gelombang. Biasanya memiliki denotasi huruf Yunani lambda $(\lambda)$. Dalam sebuah gelombang sinus, panjang gelombang adalah jarak antara puncak. 


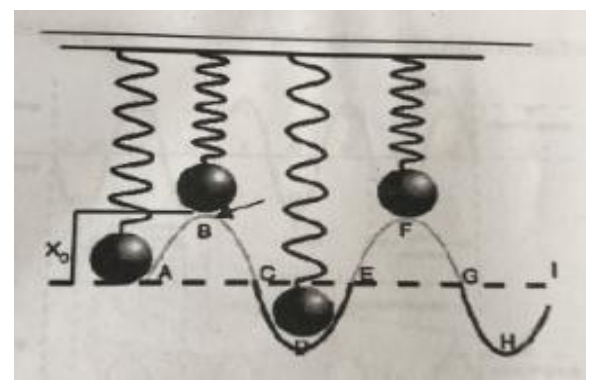

Gambar 2.4 Sifat Gelombang ${ }^{[8]}$

Amplitudo adalah pengukuran skalar yang nonnegatif dari besar suatu gelombang. Amplitudo juga dapat didefinisikan sebagai jarak/simpangan terjauh dari titik kesetimbangan dalam gelombang sinusoide yang kita pelajari pada mata pelajaran fisika dan matematika - geometrika. Amplitudo dalam sistem internasional biasa disimbolkan, dengan (A) dan memiliki satuan meter (m).

Frekuensi merupakan banyaknya getaran pada periode yang terjadi dalam satu putaran waktu. Besarnya frekuensi yang terjadi saat timbulnya vibrasi dapat mengidentifikasikan jenis-jenis gangguan yang terjadi. Cycle per menit (cpm) merupakan bentuk dari nilai frekuensi yang biasanya disebut dengan istilah $\operatorname{Hertz}(\mathrm{Hz})$.

\subsubsection{Gerak Harmonik}

Getaran dari sebuah mesin merupakan resultan dari sejumlah getaran individu komponen yang muncul. Setiap komponen individu yang bergetar memiliki gerak periodik. Gerakan akan berulang pada periode waktu pengulangan $(T)$ disebut perioda osilasi diukur dalam satuan detik dan kebalikannya adalah frekuensi ${ }^{[8]}$ dengan rumusan:

$$
f=\frac{1}{T}
$$

Frekuensi lingkaran atau kecepatan sudut dapat dihitung dengan rumus:

$$
\omega=2 \pi \frac{1}{T}=2 \pi f
$$

Kecepatan sudut $(\omega)$ biasanya diukur dalam radian per detik (rps). Bentuk sederhana dari gerak periodik adalah gerak harmonik, pada gerak harmonik, hubungan antara perpindahan maksimum dan waktu dinyatakan dengan:

$$
x=A \sin \omega t
$$

Kecepatan dalam gerak harmonik berdasarkan persamaan (2.3) dapat diperoleh dari hasil diferensial perpindahan terhadap waktu, yaitu:

$$
\frac{d x}{d t}=\dot{x}=\omega A \cos \omega t
$$

Sedangkan percepatan harmonik diperoleh dari hasil diferensial kecepatan terhadap waktu:

$$
\frac{d^{2}}{d t^{2}}=\ddot{x}=-\omega^{2} A \sin \omega t .
$$

Amplitudo melekat pada ketiga besaran perpindahan, kecepatan, dan percepatan.

\subsection{Penyebab Vibrasi}

Penyebab utama getaran adalah gaya yang berubah-ubah dalam arah dan besarnya. Karakteristik getaran yang dihasilkan bergantung pada cara bagaimana gaya penyebab getaran tersebut ditimbulkan. Hal tersebut yang menjadi alasan mengapa setiap penyebab getaran mempunyai karakteristik tertentu.

\subsubsection{Looseness}

Looseness atau yang biasa disebut mechanical looseness (Kelonggaran mekanik) adalah salah satu jenis kerusakan pada mesin yang menyebabkan terjadinya getaran. Kelonggaran mekanik dapat terjadi apabila tutup bantalan longgar atau ikatan mesin ke pondasi tidak kuat. Gejala kerusakan ini ditandai 
dengan adanya frekuensi getaran dominan pada 1/2, 1,1 1/2, 2, dst x rpm atau $\mathrm{n} x \mathrm{rpm}$ pada domain frekuensinya ${ }^{[10]}$.

Salah satu pengukuran getaran untuk mendeteksi cacat looseness pada sebuah pembangkit/turbin, menunjukkan frekuensi getaran yang lebih dominan/maksimum di 2x rpm, dan ketika diberikan beban (unbalance), frekuensi yang terjadi di 2x rpm turun drastis, dan ketika beban tersebut dihilangkan, frekuensi di 2x rpm kembali dominan ${ }^{[10]}$.

Komponen getaran yang dengan frekuensi lebih kecil dari kecepatan putar juga dapat terjadi. Teknik untuk mendeteksi kekendoran adalah dengan mengukur getaran, atau melalui signal suara pada beberapa titik (transducer kecepatan dapat berfungsi baik). Sinyal yang terukur akan mencapai maksimumnya pada arah getaran (biasanya arah vertikal memberikan getaran yang lebih besar dari arah horizontal), atau disekitar lokasi looseness. Bentuk looseness yang terjadi pada sistem berputar disajikan pada gambar.

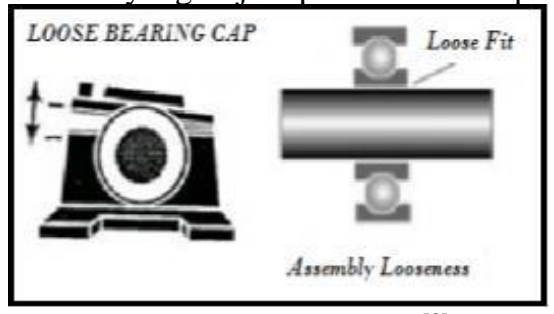

Gambar 2.5 Loosnes ${ }^{[8]}$

\subsection{Standart Pengukuran Getaran ISO 10186 dan ISO 2372}

Dalam mengindentifikasi berbagai macam kerusakan pada mesin yang dianalisis berdasarkan getarannya, maka kita menggunakan ISO 10186 dan ISO 2372 dalam prosesnya.

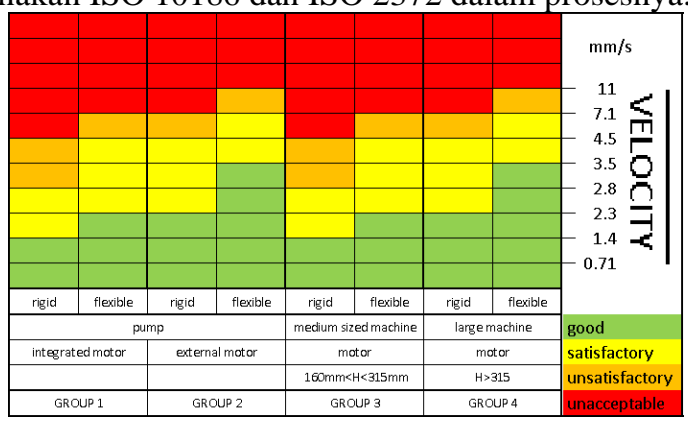

Tabel 2.1 ISO 10186 Vibration Diagnostic Table

[Sumber: Wikipedia, ISO 10186]

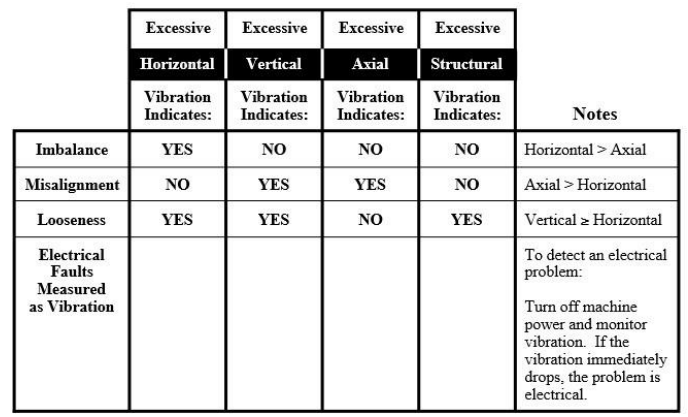

Tabel 2.2 ISO 2372 Vibration Diagnostic Table

[Sumber: SKF Reliability Systems Vibration Diagnostic Guide]

\subsection{Pengolahan Data Vibrasi}

Sinyal yang diperoleh melalui transduser pada pengukuran getaran mesin adalah gabungan berbagai respon (tanggapan) bangunan mesin terhadap bermacam-macam gaya ekstasi. Analisa yang efektif adalah menguraikan sinyal kompleks ini menjadi komponen-komponennya. Ada pandangan dalam persoalan analisis getaran menjadi komponennya, yaitu:

\subsubsection{Time Domain}

Hasil pengukuran objek pemantauan dalam time domain dapat berupa sinyal dalam Grafik. 
$>\quad$ Sinyal statik, yaitu sinyal yang karakteristiknya (misal: amplitudo, arah kerjanya) tidak berubah terhadap waktu.

$>$ Sinyal dinamik, yaitu sinyal yang karakteristiknya berubah terhadap waktu, sehingga tidak konstan.

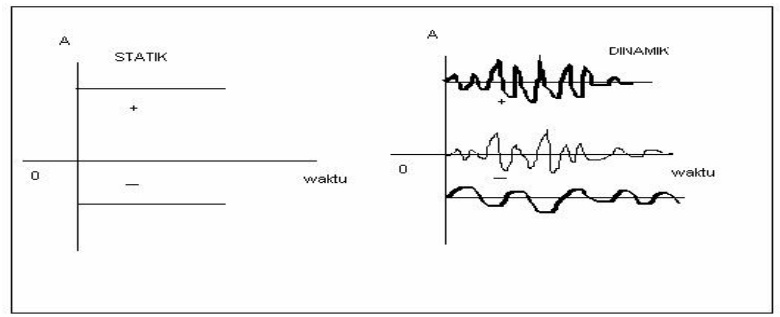

\section{Gambar 2.6 Karakterisik Sinyal Statik dan Dinamik (Ramses Y, hutahaen)}

Dalam kasus pengukuran untuk memungkinkan pengukuran objek pemantauan berupa sinyal dinamik, maka diperlukan sensor yang memiliki karakteristik dinamik tertentu. Sinyal dinamik berasal dari sinyal getaran. Untuk keperluan pengolahan sinyal getaran dalam time domain, perlu diperhatikan karakteristik sinyal getaran yang dideteksi oleh masing-masing sensor percepatan, kecepatan, dan simpangan getaran.

\subsubsection{Signal Processing Fast Fourier Transform (FFT)}

FFT adalah algoritma matematika yang dikomputerisasi untuk mentransformasi sinyal vibrasi dari domain waktu (time waveform) ke domain frekuensi. FFT menghasilkan gambaran amplitudo vibrasi terhadap frekuensi. Pada analisa vibrasi, frekuensi merupakan parameter yang dianalisa untuk menemukan gangguan pada mesin. Analisa dapat dilakukan saat mesin sedang beroperasi.

Misalnya, kami mengukur amplitudo sinyal pada $10 \mathrm{~Hz}$, kemudian lagi pada $20 \mathrm{~Hz}$, dll., Hingga kami memiliki daftar nilai untuk setiap frekuensi yang terkandung dalam sinyal. Nilai atau amplitudo ini kemudian diplotkan pada skala frekuensi. Jumlah frekuensi komponen yang bentuk gelombangnya dibagi disebut sebagai jumlah garis resolusi. Plot yang dihasilkan disebut spektrum FFT.

Spektrum FFT adalah alat yang sangat berguna. Jika ada masalah mesin, spektrum FFT memberikan informasi untuk membantu menentukan lokasi masalah, penyebab masalah dan, dengan tren, berapa lama sampai masalah menjadi kritis. Karena kita tahu bahwa masalah mesin tertentu terjadi pada frekuensi tertentu, kami menganalisis spektrum FFT dengan mencari perubahan amplitudo dalam rentang frekuensi tertentu.

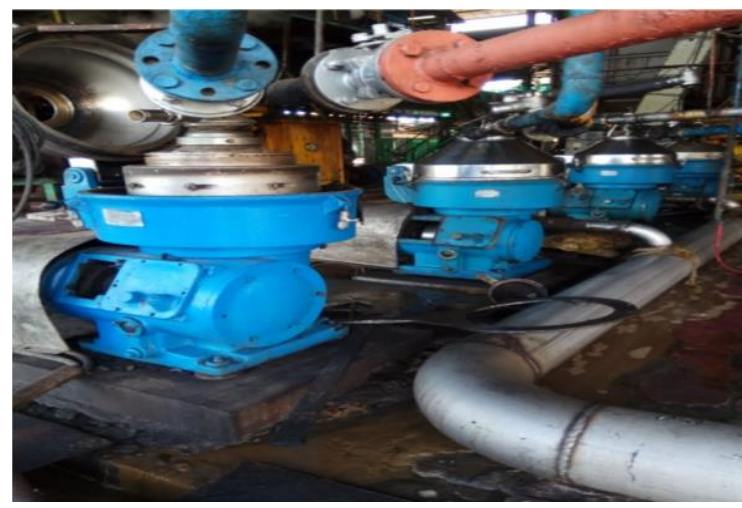

Gambar 2.7 Fast Fourier Transform Method

\section{HASIL DAN PEMBAHASAN}

\subsection{Peralatan Pengujian}

\subsubsection{Objek Uji}

Pada usulan penelitian ini, objek yang dianalisa adalah sistem transmisi pada mesin sludge separator dalam pabrik kelapa sawit. Objek mesin diamati dan dianalisa selama kurun waktu tertentu menggunakan alat komputasi dan eksperimental. Pengukuran dilakukan pada casing dari mesin tersebut. 


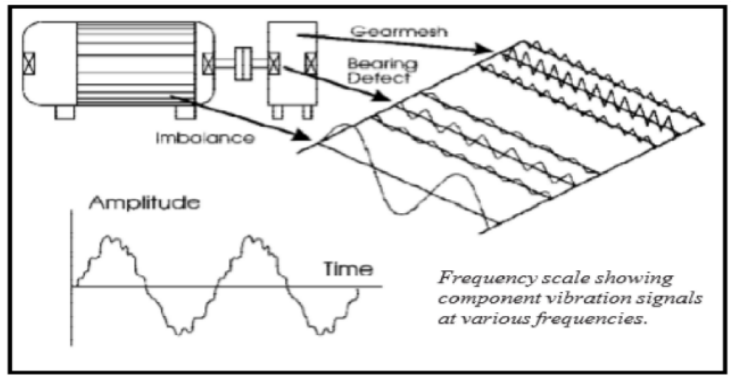

Gambar 3.1 Sludge Separator Sebagai Objek Penelitian

Tabel 3.1 Spesifikasi Sludge Separator

\begin{tabular}{|l|l|}
\hline Produksi & $\begin{array}{l}\text { Separatech } \\
\text { Mechanical Servicing } \\
\text { \& Supply SDN.BHD }\end{array}$ \\
\hline Manufacturing & 2012 \\
\hline Tipe & $\begin{array}{l}\text { Paml Oil Centrifuge } \\
\text { SMSS 410 }\end{array}$ \\
\hline Power & $17 \mathrm{kw}(23 \mathrm{Hp})$ \\
\hline $\begin{array}{l}\text { Kecepatan putaran } \\
\text { motor penggerak (N) }\end{array}$ & $1450 \mathrm{Rpm}$ \\
\hline $\begin{array}{l}\text { Transmisi ( Roda Gigi } \\
\text { Cacing) }\end{array}$ & $\mathrm{i}=63: 13$ \\
\hline Kecepatan putaran bowl & 5200-5400 Rpm \\
\hline Kapasitas & $7000 \mathrm{~L} / \mathrm{Jam}$ \\
\hline
\end{tabular}

\subsubsection{Alat Ukur}

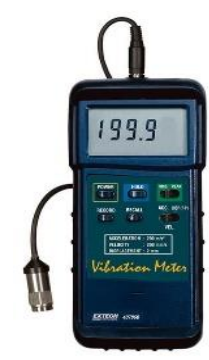

Gambar 3.2 Vibration meter

Vibration meter adalah alat yang digunakan untuk mengukur getaran sebuah benda, misalnya motor, pompa, atau benda bergetar lainnya terutama dalam dunia industri. Cara kerja alat ini adalah dengan menempelkan vibration sensornya ke benda/ mesin yang akan diukur kemudian vibration meter akan menampilkan nilai kuatnya getaran pada layar.

\subsection{Pengukuran dan Analisa Getaran}

Tabel 3.2 Data Hasil Pengukuran Vibrasi pada Titik 6 Cassing Sludge Separator

\begin{tabular}{|c|c|c|c|}
\hline & \multicolumn{3}{|c|}{6} \\
\hline SUMBU & A6 & H6 & V6 \\
\hline TIME & & & \\
\hline 0.25 & 3.61 & 4.23 & 5.43 \\
\hline 0.5 & 3.54 & 4.42 & 5.23 \\
\hline 0.75 & 3.45 & 5.11 & 4.91 \\
\hline 1 & 3.64 & 4.69 & 5.32 \\
\hline 1.25 & 3.41 & 4.77 & 4.52 \\
\hline 1.5 & 3.22 & 4.44 & 4.33 \\
\hline 1.75 & 3.89 & 4.26 & 4.66 \\
\hline 2 & 3.78 & 4.59 & 4.82 \\
\hline 2.25 & 3.67 & 4.37 & 4.79 \\
\hline 2.5 & 3.37 & 4.86 & 4.78 \\
\hline
\end{tabular}




\begin{tabular}{|c|c|c|c|}
\hline 2.75 & 3.63 & 4.78 & 4.99 \\
\hline 3 & 3.37 & 4.51 & 4.77 \\
\hline 3.25 & 3.44 & 4.73 & 4.81 \\
\hline 3.5 & 3.51 & 5.11 & 4.91 \\
\hline 3.75 & 3.59 & 4.68 & 4.87 \\
\hline 4 & 3.47 & 4.32 & 5.11 \\
\hline
\end{tabular}
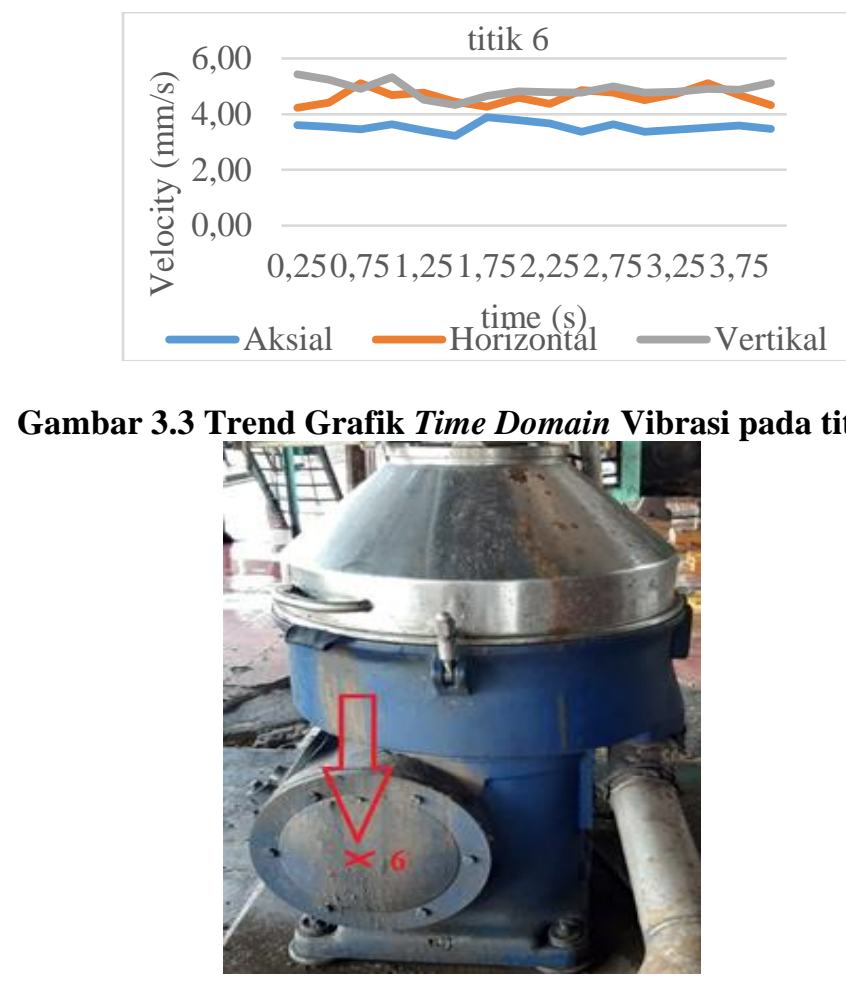

\section{Gambar 3.4 Posisi Pengukuran pada titik 6}

Getaran pada titik 6 arah Aksial menunjukkan velocity getaran paling rendah terjadi pada detik 1.5 dengan getaran $3.22 \mathrm{~mm} / \mathrm{s}$ sedangkan yang paling tinggi terjadi pada detik 1.75 dengan getaran 3.89 $\mathrm{mm} / \mathrm{s}$. Rata- rata getaran pada arah Aksial adalah $3.54 \mathrm{~mm} / \mathrm{s}$.

Getaran pada titik 6 arah Horizontal menunjukkan velocity getaran paling rendah terjadi pada detik 1.75 dengan getaran $4.26 \mathrm{~mm} / \mathrm{s}$ sedangkan yang paling tinggi terjadi pada detik 2 dengan getaran 5.34 $\mathrm{mm} / \mathrm{s}$. Rata- rata getaran pada arah Horizontal adalah $4.87 \mathrm{~mm} / \mathrm{s}$.

Getaran pada titik 6 arah Vertikal menunjukkan velocity getaran paling rendah terjadi pada detik 1.5 dengan getaran $4.33 \mathrm{~mm} / \mathrm{s}$ sedangkan yang paling tinggi terjadi pada detik 0.25 dengan getaran 5.43 $\mathrm{mm} / \mathrm{s}$. Rata- rata getaran pada arah vertikal adalah $4.89 \mathrm{~mm} / \mathrm{s}$.

Secara keseluruhan dapat dilihat bahwa dari sumbu aksial, horizontal dan vertikal kita dapat melihat terjadinya ketidaksesuaian pada sludge separator di titik 6 ini dengan getaran pada sumbu aksial lebih rendah dari sumbu horizontal dan vertikal.

\subsection{Grafik frekuensi domain Vibrasi Pada Titik 6 (arah Aksial)}

Tabel 3.3 Fast Fourrier Transform data Aksial pada titik 6

\begin{tabular}{|c|c|}
\hline freq & IMABS \\
\hline 0.25 & 56.59 \\
\hline 0.5 & 0.383807 \\
\hline 0.75 & 0.851028 \\
\hline 1 & 0.636643 \\
\hline 1.25 & 0.75452 \\
\hline 1.5 & 0.914431 \\
\hline 1.75 & 0.381513 \\
\hline 2 & 0.496784 \\
\hline
\end{tabular}




\begin{tabular}{|c|c|}
\hline 2.25 & 0.79 \\
\hline 2.5 & 0.496784 \\
\hline 2.75 & 0.381513 \\
\hline 3 & 0.914431 \\
\hline 3.25 & 0.75452 \\
\hline 3.5 & 0.636643 \\
\hline 3.75 & 0.851028 \\
\hline 4 & 0.383807 \\
\hline
\end{tabular}

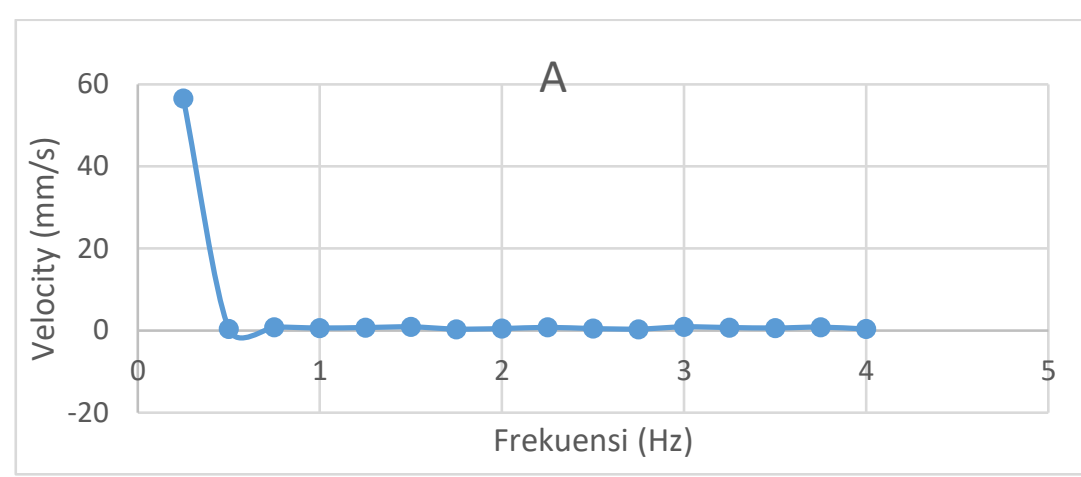

Gambar 3.5 Trend Grafik Frekuensi Domain Aksial pada titik 6

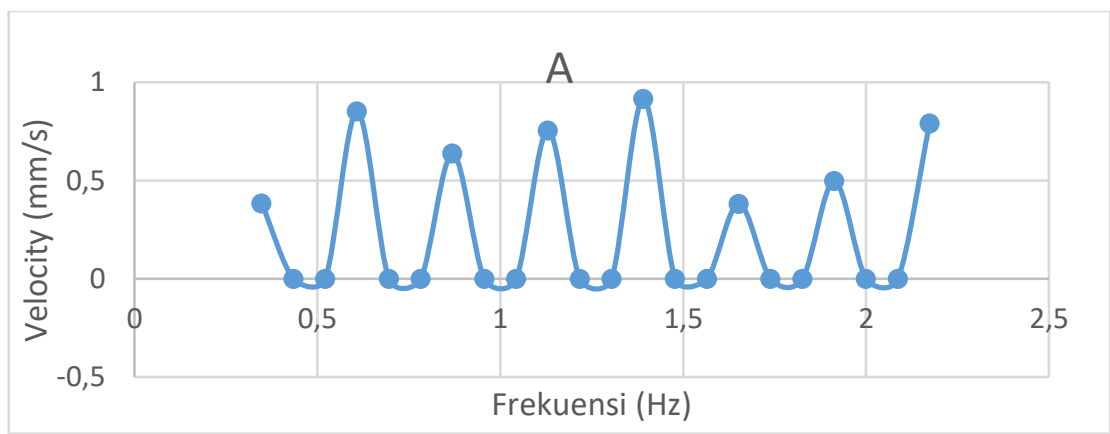

Gambar 3.6 Trend Grafik Frekuensi Domain Aksial pada titik 6

Grafik frekuensi domain titik 6 diperoleh dari pengolahan data pada exel dan setiap data diplot berdasarkan hasil fast fourrier transform seperti table, grafik 3.5 merupakan plot data secara keseluruhan hasil fast fourrier transform. Kemudian grafik dibagi 2 seperti gambar 3.6. Hal ini dilakukan agar data dapat dilihat lebih jelas dan tidak saling mendistraksi antar satu data dengan data yang lain.

Berdasarkan dari data hasil pengukuran pada tabel 4.1, data yang dihasilkan adalah berupa hasil kecepatan. Sehingga berdasarkan data vibrasi yang didapatkan maka digambarkan karakteristik vibrasi dengan langkah sebagai berikut:

Kecepatan sudut pada kecepatan putaran poros : $1450 \mathrm{Rpm}$, maka :

$$
\begin{gathered}
\varpi=\frac{2 \pi}{60} x n \\
\varpi=\frac{2 \pi}{60} x 1450=151,76 \mathrm{rad} / \mathrm{s}
\end{gathered}
$$

Frekuensi motor dapat dihitung :

$$
\varpi=2 \pi f, \text { sehingga } f=\frac{\varpi}{2 \pi}
$$

Maka:

$$
f=\frac{\varpi}{2 \pi}=\frac{151,76}{2 \pi}=24,16 \mathrm{~Hz}
$$

Sehingga Perioda motor dapat dihitung adalah sebagai berikut:

$$
T=\frac{1}{f}=\frac{1}{24,16}=0,041 \mathrm{~s}
$$

Amplitudo dapat dihitung melalui persamaan velocity yang di dapat dari hasil transduser, dengan demikian persamaan amplitudo dapat dihitung sebagai berikut :

$$
\begin{gathered}
\dot{x}=\varpi A \cdot \cos \varpi t \\
A=\frac{\dot{x}}{\varpi \cos \varpi t}
\end{gathered}
$$




$$
A=\frac{3,61}{151,76 \cos (151,76) \cdot 0,25}=0,0301 \mathrm{~mm} / \mathrm{s}
$$

Untuk menghitung acceleration dapat dicari dengan mendifferensialkan persamaan velocity sebagai berikut:

$$
\begin{gathered}
\ddot{x}=\frac{d \ddot{x}}{d t} \\
\ddot{x}=\frac{d(\varpi A \cdot \cos \varpi t)}{d t} \\
\ddot{x}=-\varpi^{2} A \sin \varpi t \ddot{x}=-(151,76)^{2} \cdot 0,0301 \sin (151,76) \cdot 0,25 \\
\ddot{x}=427,11 \mathrm{~mm} / \mathrm{s}^{2}
\end{gathered}
$$

Dari hasil perhitungan acceleration yang didapat dari mendifferensialkan persamaan velocity dapat dilihat pada table 3.4 sebagai berikut :

Tabel 3.4 Hasil Pengukuran Acceleration pada titik 6

\begin{tabular}{|c|l|l|l|}
\hline & \multicolumn{3}{|c|}{ Titik 6} \\
\hline SUMBU & $\mathrm{A} 6$ & $\mathrm{H} 6$ & $\mathrm{~V} 6$ \\
\hline TIME & $\mathrm{mm} / \mathrm{s}^{2}$ & $\mathrm{~mm} / \mathrm{s}^{2}$ & $\mathrm{~mm} / \mathrm{s}^{2}$ \\
\hline $\mathbf{0 . 2 5}$ & 427.11 & 500.46 & 642.44 \\
\hline $\mathbf{0 . 5}$ & 418.83 & 522.94 & 618.77 \\
\hline $\mathbf{0 . 7 5}$ & 408.18 & 604.58 & 580.91 \\
\hline $\mathbf{1}$ & 430.66 & 554.88 & 629.42 \\
\hline $\mathbf{1 . 2 5}$ & 403.44 & 564.35 & 534.77 \\
\hline $\mathbf{1 . 5}$ & 380.97 & 525.31 & 512.29 \\
\hline $\mathbf{1 . 7 5}$ & 460.23 & 504.01 & 551.33 \\
\hline $\mathbf{2}$ & 447.22 & 543.05 & 569.71 \\
\hline $\mathbf{2 . 2 5}$ & 434.21 & 517.02 & 566.36 \\
\hline $\mathbf{2 . 5}$ & 398.71 & 575.00 & 565.37 \\
\hline $\mathbf{2 . 7 5}$ & 429.47 & 565.53 & 590.38 \\
\hline $\mathbf{3}$ & 398.71 & 533.59 & 564.57 \\
\hline $\mathbf{3 . 2 5}$ & 406.99 & 559.62 & 569.08 \\
\hline $\mathbf{3 . 5}$ & 415.28 & 604.58 & 580.91 \\
\hline $\mathbf{3 . 7 5}$ & 424.74 & 553.70 & 576.18 \\
\hline $\mathbf{4}$ & 410.54 & 511.11 & 604.58 \\
\hline
\end{tabular}

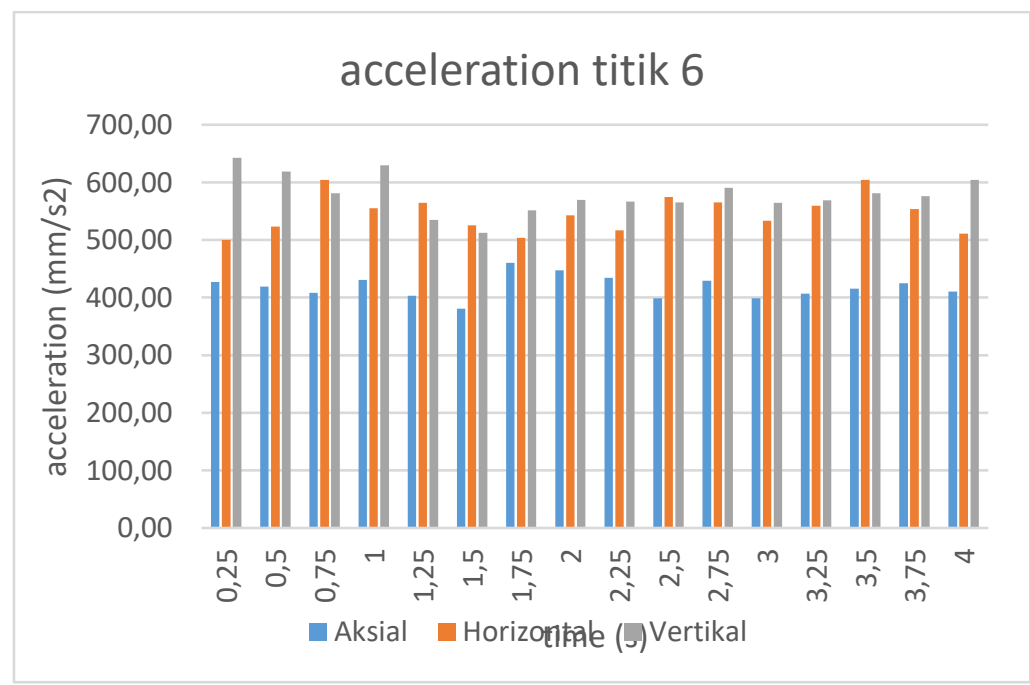

\section{Gambar 3.7 Grafik Acceleration vs Time}

Dapat dilihat dari gambar grafik acceleration bahwa untuk amplitudo yang dihasilkan memiliki amplitudo terbesar pada arah vertikal

Untuk menghitung displacement dapat dicari dengan mengintegralkan persamaan velocity sebagai berikut: 


$$
\begin{gathered}
x=\int \dot{x}(t) \\
x=A . \sin \omega t \\
x=0.030162 \sin (151,76) .0,25 \\
x=0,019
\end{gathered}
$$

Dari hasil perhitungan displacement yang didapat dengan mengintegralkan persamaan velocity dapat dilihat pada tabel 3.5

Tabel 3.5 Hasil Pengukuran Displacement pada titik 6

\begin{tabular}{|c|l|l|l|}
\hline & \multicolumn{3}{|c|}{ Displacement } \\
\hline SUMBU & A & \multicolumn{1}{l|}{$\mathrm{H}$} & $\mathrm{V}$ \\
\hline TIME & $\mathrm{mm}$ & $\mathrm{mm}$ & $\mathrm{mm}$ \\
\hline $\mathbf{0 . 2 5}$ & 0.019 & 0.022 & 0.028 \\
\hline $\mathbf{0 . 5}$ & 0.093 & 0.116 & 0.137 \\
\hline $\mathbf{0 . 7 5}$ & 0.051 & 0.076 & 0.073 \\
\hline $\mathbf{1}$ & 0.013 & 0.017 & 0.019 \\
\hline $\mathbf{1 . 2 5}$ & 0.004 & 0.005 & 0.005 \\
\hline $\mathbf{1 . 5}$ & 0.023 & 0.032 & 0.031 \\
\hline $\mathbf{1 . 7 5}$ & 0.332 & 0.363 & 0.397 \\
\hline $\mathbf{2}$ & 0.038 & 0.046 & 0.048 \\
\hline $\mathbf{2 . 2 5}$ & 0.008 & 0.01 & 0.011 \\
\hline $\mathbf{2 . 5}$ & 0.008 & 0.011 & 0.011 \\
\hline $\mathbf{2 . 7 5}$ & 0.037 & 0.049 & 0.051 \\
\hline $\mathbf{3}$ & 0.24 & 0.322 & 0.34 \\
\hline $\mathbf{3 . 2 5}$ & 0.024 & 0.033 & 0.034 \\
\hline $\mathbf{3 . 5}$ & 0.004 & 0.005 & 0.005 \\
\hline $\mathbf{3 . 7 5}$ & 0.013 & 0.017 & 0.018 \\
\hline $\mathbf{4}$ & 0.054 & 0.067 & 0.079 \\
\hline
\end{tabular}

3.4 Analisa Gejala/ Kondisi Terkini Berdasarkan ISO 10186 dan ISO 2372

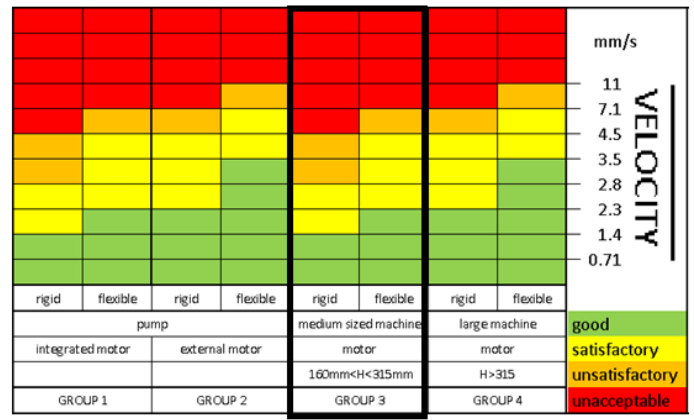

Tabel 3.6 ISO 10186 Vibration Diagnostic Table

Dalam mengidentifikasi berdasarkan tabel 3.6 penulis menyesuaikan posisi mesin sludge separator yang di uji dalam grup 3 dengan ukuran mesin sedang yang rigid dengan velocity maksimal 4,5 mm/s. Rata- rata Velocity yang terjadi pada tiap titik adalah sebagai berikut :

Tabel 3.7 Diagnosa Getaran pada titik 6 dalam ISO 2372

\begin{tabular}{|l|l|l|l|l|l|}
\hline \multirow{2}{*}{ Axis } & MIN & MAX & AVARAGE & STATUS & \multirow{2}{*}{ DIAGNOSA } \\
\cline { 2 - 5 } Aksial & 3.22 & 3.89 & 3.54 & $\begin{array}{l}\text { NO (GOOD- } \\
\text { SATISFACTORY) }\end{array}$ & \\
\cline { 1 - 4 } Horizontal & 4.26 & 5.34 & 4.87 & $\begin{array}{l}\text { YES } \\
\text { (UNSATISFACTORY- } \\
\text { UNACCEPABLE) }\end{array}$ & LOOSENESS \\
\cline { 1 - 4 } Uertikal & 4.33 & 5.43 & 4.89 & $\begin{array}{l}\text { YES } \\
\text { (UNSATISFACTORY- } \\
\text { UNACCEPTABLE) }\end{array}$ & \\
\hline
\end{tabular}


Berdasarkan ISO 2372 status NO sama dengan level good - satisfactory $(0 \mathrm{~mm} / \mathrm{sec} \leq \mathrm{x}<4.5$ $\mathrm{mm} / \mathrm{sec}$ ) dalam ISO 10183 sedangkan status YES sama dengan unsatisfactory - unacceptable (4.5 $\mathrm{mm} / \mathrm{sec} \leq \mathrm{x}<\infty \mathrm{mm} / \mathrm{sec})$.

\section{KESIMPULAN DAN SARAN}

\subsection{Kesimpulan}

Berdasarkan dari pengujian yang dilakukan maka dapat disimpulkan sebagai berikut :

1. Berdasarkan dari hasil komputasi maka ditentukan posisi pengukuran vibrasi pada 6 titik, pola getaran yang terjadi pada titik 1 dan 2 tercatat hasil kecepatan getaran masih dibawah $2.8 \mathrm{~mm} / \mathrm{s} \mathrm{di}$ setiap arah getarannya, sedangkan pada titik 3,4,5 dan 6 sudah mencapai batas tidak memuaskan pada arah horizontal dan vertikal karena sudah mencapai batas kecepatan getaran 4,5 mm/s sesuai dengan standar ISO 10816.

2. Amplitudo aksial terbesar terjadi pada pada titik 6 dengan kecepatan getaran $3,22 \mathrm{~mm} / \mathrm{s}$, amplitudo horizontal terbesar terjadi pada titik 5 dengan $5,54 \mathrm{~mm} / \mathrm{s}$ dan amplitudo vertikal terbesar terjadi pada titik 5 dengan $5,72 \mathrm{~mm} / \mathrm{s}$. Displacement terbesar terjadi pada arah vertikal pada titik 6 sebesar 0,376 mm. secara keseluruhan dari data kecepatan getaran mesin ini memiliki gejala kerusakan.

3. Berdasarkan data pengukuran menunjukkan karakteristik kerusakan pada titik 1,2 belum terlihat karena pengukuran dilakukan pada putaran rendah. Sedangkan karakteristik kerusakan pada titik 3,4,5,6 adalah gejala Mechanical Looseness. Tingkat keadaan yang sudah melampaui batas normal terdeteksi karena munculnya sinyal amplitudo tinggi pada arah horizontal dan vertikal sedangkan tidak muncul di arah aksial (ISO 10816, ISO 2372).

\subsection{Saran}

Saran untuk penelitian ini adalah :

1. Peneliti perlu untuk megembangkan sebuah perangkat ukur yang dapat secara langsung menerima data vibrasi yang terukur lalu menerjemahkannya kedalam karakteristik kerusakan yang dialami oleh mesin tersebut, dimana proses deteksi dilakukan secara terpadu dan terintegrasi antara setiap komponen.

2. Pengukuran dilakukan dengan berbagai alternatif seperti pengukuran berbasis bunyi agar dapat dibandingkan hasil pengukuran nya.

3. Melakukan predictive maintenance pada profil roda gigi atau bearing untuk memastikan tidak adanya gejala kerusakan yang terjadi sehingga mesin dapat beroperasi dengan baik.

\section{REFERENSI}

[1] Bur, M., Okuma, M., Malta, J., Huda, F. 2005. Experimental Study of Vibration on Rotor System Due to Unbalance Mass and Misalignment. Jurnal Poros Vol 8 No 4, 24-234.

[2] Fariha, Aidil Othman. 2008. "Vibration Analysis for Diagnostic of Local Faults in Rolling Element Bearing”. Thesis. Universiti Teknikal Malaysia Melaka.

[3] Harris, Cyril M \& Allan G. Piersol (Eds), 2002. "Shock \& Vibration Handbook” Fifth Edition, Mc. Graw-Hill Companies, New York.

[4] Harsanto, Budi. 2013. Dasar Ilmu Manajemen Operasi. Bandung : UNPAD.

[5] Kapidzic, Z., H. Ansell, J. Schon and K. Simonsson.2015. "Fatigue bearing failure of CFRP composite in biaxially loaded bolted joints at elevated temperature. Composite Structures ; 127: 298-307.

[6] Mobley, R. K; Lindley R. Higgins dan Darrin J. Wikoff. 2008 : Maintenance Enginering Handbook"., Seventh Edition, NewYork, McGraw-Hill Book Company.

[7] Suhardjono, 2004, Analisis Sinyal Getaran untuk Menentukan Jenis dan Tingkat Kerusakan Bantalan Bola (Ball Bearing), Jurnal Teknik Mesin, Vol. 6, No. 2, Hal. 39-48.

[8] Scheffer C. dan Girdhar P.2004. "Practical Machinery Vibration Analysis and Predictive Maintenance". Amsterdam: IDC Technologies.

[9] Vierck. K Robert.1995. “Analisis Getaran” PT Eresco. Bandung.

[10] V. Wowk.1991. “Machinery Vibration”, New York : McGraw-Hill,Inc.

[11] William T. Thomson.1992 “Teori Getaran Dengan Penerapannya”. Edisi Kedua Erlangga.

[12] Purnama, A. dan Ariosuko. 2014. Analisis Perbandingan Sifat Fisis dan Mekanis Bantalan Peluru Baru, Telah Dipakai dan Rusak untuk Kendaraan Bermotor Roda Dua. SINERGI.; 18(2):92-98 